Artigos

\title{
Vulnerabilidade e perigo potencial - 0 processo de criminalização do assédio sexual online no Canadá e casos julgados em Ontário (2002-1014)
}

Tatiana Savoia Landini²

Resumo: A massificação da Internet, nos idos de 1990, e o mais recente desenvolvimento e fácil acesso às novas tecnologias de comunicação e informação trouxe a violência sexual cometida no ambiente online como foco de atenção para aqueles preocupados com a proteção de crianças e adolescentes. Na esteira das discussões sobre pornografia infantil, tomaram corpo as discussões sobre grooming ou luring, traduzidos para o português como assédio sexual, aliciamento ou sedução online. Neste texto, reflito sobre o movimento de criminalização do chamado online luring ou online grooming, no Canadá, além de fazer algumas reflexões também a partir da análise de relatórios judiciais de casos julgados por assédio sexual na Província de Ontario, entre os anos de 2002 e 2014. A partir de 2002, a seção 172.1 do Código Criminal passou a proibir a comunicação entre um adulto e uma criança, via tecnologias da comunicação e da informação, quando esta pode ou poderia resultar em um crime sexual. Este artigo tem

1 Este texto resulta da pesquisa Assédio sexual online e pornografia infantil - um estudo dos casos julgados na província de Ontário, Canadá, realizada com apoio da FAPESP, por meio de Bolsa de Pesquisa no Exterior. Agradeço a Patrice Corriveau pela recepção no Departamento de Criminologia da Universidade de Ottawa. (Processo Fapesp no 2013/26401-1)

2 Escola de Filosofia, Letras e Ciências Humanas - Universidade Federal de São Paulo (Unifesp) - São Paulo - Brasil - tatiana.landini@unifesp.br 
como foco não o assédio em si, mas as crenças, valores e ideologias que estão em pauta, sendo discutidas as representações da criança, do adulto agressor e do ambiente online, pilares que sustentaram o processo de criminalização do assédio online e que estão presentes também nos registros dos casos julgados por esse crime.

Palavras-chaves: Violência sexual; crianças e adolescentes; assédio sexual; representação; Norbert Elias.

\section{VULNERABILITY AND ITS POTENTIAL PERILS - ON THE CRIMINAL- IZATION OF ONLINE LURING IN CANADA AND COURT CASES TRIED IN ONTARIO (2002-2014)}

Abstract: The mass diffusion of the Internet since the 1990 and the development and expansion of easy access to information and communication technologies placed online sexual violence as a focus of attention for those concerned with child and adolescent protection. In the wake of the usual discussions on child pornography, an increasing concern has emerged about situations of online grooming or luring. This article reflects on Canada's movement to criminalize online luring/ grooming, and makes some remarks based on Court Reports from the province of Ontario in the years 2002 to 2014. From 2002 on, Section 172.1 of the Criminal Code of Canada prohibits communications between adults and children via information and communication technologies that could result in a sexual offence. The study is not focused on luring in itself, but on the beliefs, values and ideologies identified in its agenda. It discusses the representations of children, adult offenders and online environment that stand as the foundations of the process of criminalizing online luring, and are also found in the reports of the studied cases and decisions in connection with the crime.

Keywords: Sexual violence; Children and adolescents; Luring; Representation; Norbert Elias.

A massificação da Internet, nos idos de 1990, e o mais recente desenvolvimento e fácil acesso às novas tecnologias de comunicação e informação (conexão de telefones celulares, smart phones e tablets às redes $3 \mathrm{G} \mathrm{e} 4 \mathrm{G}$ ) trouxe a violência sexual cometida no ambiente online como foco de atenção para aqueles preocupados com a proteção de crianças e adolescentes. A preocupação voltou-se, primeiramente, para a produção, troca e comercialização da pornografia via 
Internet, posteriormente também utilizando outras tecnologias da informação e da comunicação. Na esteira, as atenções voltaram-se para a relação entre o online e o offline, entre o crime ocorrido no âmbito da Internet (ou mediados pelas tecnologias da comunicação e da informação) e crimes ocorridos fora desse âmbito. É apenas nesse momento que toma corpo a discussão sobre grooming ou luring, traduzidos para o português como assédio sexual, aliciamento ou sedução online.

O presente texto tem como foco de reflexões justamente o processo de criminalização do assédio sexual online. O espaço geográfico é o Canadá, um dos primeiros ou talvez o primeiro país no mundo a aprovar legislação a esse respeito. De forma bastante precisa: minhas reflexões têm como ponto de partida o movimento de criminalização do chamado online luring ou online grooming, discussão levada a cabo pelo Parlamento Canadense e que redundou na aprovação do Artigo 172.1 do Código Criminal em 2002. Utilizo como fonte de reflexão também relatórios judiciais de casos julgados por assédio sexual online na Província de Ontário entre os anos de 2002 e 2014.

Mas alerto desde já: este texto não é sobre assédio sexual em si, mas sobre as crenças, valores e ideologias que estão em pauta e que dão sustentação ao processo de criminalização do assédio. Para tanto, parto da noção de representação. Afirma Porto (2010: 76) que há diferença entre a realidade da violência e sua representação: a primeira possui um componente objetivo, é o que os números e as estatísticas assinalam; a segunda possui um componente subjetivo e diz respeito ao que indivíduos e sociedade reputam (representam) como violência. O processo de criminalização de um ato é uma oportunidade ímpar para refletir sobre questões que circundam e dão sustentação ao processo. Na terminologia durkheiminiana, pratica-se uma sociologia da moral ao tomar os valores e a moral como objeto de estudo.

Seguimos por essa linha, portanto.

\section{Para início de conversa: 0 que é assédio/grooming?}

O conceito de assédio sexual/ grooming a fim de facilitar o abuso sexual de uma criança não é novo. Mas, antes de ser um crime definido no Código Criminal do Canadá - e de vários outros países -, essa era uma ferramenta conceitual originária do campo da psicologia. Mesmo não utilizando a palavra assédio ou grooming, David Finkelhor, um dos primeiros e mais reconhecidos acadêmicos a teorizar sobre o abuso sexual de crianças, tocou nesse assunto em um livro publicado em 1984. Neste livro, ele apresenta um modelo de quatro pré-condições que viabilizam o abuso sexual: 1) o agressor potencial precisa ter motivação 
para abusar de uma criança; 2) ele/ ela precisa superar inibições internas; 3) também precisa superar obstáculos externos; e 4) deve superar a resistência da criança a um possível abuso sexual (Finkelhor, 1984: 54). Esta última condição pode ser entendida como o processo de assédio/ grooming da criança/ adolescente que precede e possibilita a ocorrência do abuso sexual.

O grooming "envolve um processo de socialização por meio do qual um ofensor busca interagir com a criança (...), possivelmente compartilhando de seus interesses numa tentativa de ganhar sua confiança e prepará-la para o abuso sexual" (Davidson, 2011: 10). McAlinden (2012: 11) possui uma definição um pouco mais extensa de assédio/ grooming, entendendo-o como "1) o uso de uma variedade de técnicas manipulativas e de controle 2) com um sujeito vulnerável 3) em uma variedade de cenários interpessoais e sociais 4) a fim de estabelecer confiança ou normalizar comportamentos sexuais prejudiciais 5) com o objetivo final de facilitar a exploração e/ou proibir a exposição". O assédio/ grooming pode, portanto, ocorrer em uma variedade de contextos (intrafamiliares e extrafamiliares) e a partir de diferentes abordagens (contatos face a face, atividades via Internet ou online, grooming de rua ou grooming entre pares) (McAlinden, 2012: 28).

O desenvolvimento dos meios de informação e comunicação deu novo ímpeto a essa discussão. Assim que a Internet se tornou um importante e difundido meio de comunicação, seguiu-se um medo de que pudesse ser utilizada para facilitar o contato entre adultos e potenciais vítimas de abuso sexual, como crianças e adolescentes. Nos idos de 1997, quando a massificação da Internet estava em seu início, Durkin escreveu que havia quatro formas por meio das quais a Internet estava sendo utilizada de maneira imprópria por pedófilos: ${ }^{3}$ para traficar pornografia infantil, para localizar crianças para molestar, para comunicações sexualizadas inapropriadas com crianças e adolescentes e para estabelecer contatos com outros pedófilos. Outros autores desenharam uma linha causal entre a pornografia infantil e o assédio/ grooming. A tipologia ${ }^{4}$ da pornografia infantil desenvolvida por Krone (2004), por exemplo, inclui um nível denominado "groomer" e outro denominado "abusador físico". O "groomer" é aquele que cultiva "uma relação online com uma ou mais crianças" e o "abusador físico"

3 A pedofilia é definida pela Classificação Internacional de Doenças (CID 10) como um transtorno de preferência sexual, em que a pessoa tem preferência sexual por crianças, meninos, meninas ou ambos, usualmente em idade pré-puberal ou em início de puberdade. Apesar de Durkin utilizar a palavra pedófilo, lembro que, ainda que existam pedófilos que utilizam as tecnologias da comunicação e da informação para entrar em contato com crianças, o problema do assédio sexual online não se restringe a esse grupo.

4 A tipologia desenvolvida por Krone possui 9 níveis, cada um dos quais refletindo um grau de seriedade maior que o anterior: browser, fantasia privada; trawler; colecionador não seguro; colecionador seguro; groomer; abusador físico; produtor; e distribuidor. 
é aquele que abusa de "uma criança que talvez tenha sido apresentada ao abusador no ambiente online". Em ambos os casos, segundo ele, "a pornografia pode ser utilizada para facilitar o abuso".

O início dos anos 2000 marca o começo de um processo de criminalização do assédio/ grooming online. Quando ocorre no ambiente online, a comunicação com uma criança ou adolescente com o objetivo de cometer abuso sexual deixou de ser entendida como um "estágio" ou "pré-condição" para o abuso sexual e passou a ser entendida como um comportamento independente que deveria ser não apenas fortemente reprovado, mas também criminalizado. Até o momento, não são tantos os países que aprovaram leis específicas contra o assédio/ grooming, sendo alguns deles Estados Unidos, Canadá, Austrália, Reino Unido e Irlanda, Noruega, Suécia e Holanda. ${ }^{5}$

O Parlamento do Canadá aprovou o Artigo 172.1, do Código Criminal em 2002, no qual se lê: 6

172.1 (1) Comete ofensa toda pessoa que, por qualquer meio de telecomunicação, comunica-se com

(a) uma pessoa que seja, ou que o acusado acredite ser, menor de 18 anos, com o objetivo de facilitar a comissão de uma ofensa sob a subseção 153(1) [exploração sexual], seção 155 [incesto], 163.1 [pornografia infantil], 170 [pais ou responsáveis que procuram atividade sexual] ou 171 [permitir atividade sexual em sua propriedade] ou subseção 212(1), (2), (2.1) ou (4) [proxenetismo e prostituição] com respeito àquela pessoa;

(b) uma pessoa que seja, ou que o acusado acredite ser, menor de 16 anos, com o objetivo de facilitar a comissão de uma ofensa sob a seção 151 [interferência sexual] ou 152 [convite ao toque sexual], subseção 160(3) [bestialidade na presença de uma criança] ou 173(2) [exposição] ou seção 271 [agressão sexual], 272 [agressão sexual com arma], 273 [agressão sexual agravada] ou 280 [sequestro de pessoa menor de 16 anos] com respeito àquela pessoa; ou (c) uma pessoa que seja, ou que o acusado acredite ser, menor de 14 anos, com o objetivo de facilitar a comissão de uma ofensa sob a seção 281 [sequestro de uma pessoa menor de 14 anos] com respeito àquela pessoa.

5 Na legislação brasileira, a criminalização do assédio sexual ocorreu em 2008, a partir de modificações introduzidas à legislação sobre pornografia infantil (art. 241 do Estatuto da Criança e do Adolescente (ECA)), portanto, permanecendo o assédio relacionado à pornografia infantil. Uma das modificações foi justamente a inclusão do artigo 241-D no Estatuto da Criança e do Adolescente (ECA), que trata do tema em questão: "Art. 241-D. Aliciar, assediar, instigar ou constranger, por qualquer meio de comunicação, criança, com o fim de com ela praticar ato libidinoso" (Incluído pela Lei n 11.829, de 2008). 
A legislação canadense proíbe, portanto, a comunicação entre um adulto e uma criança, via tecnologias da informação e da comunicação, quando há possibilidades de que resulte em um crime sexual. A possibilidade de que fala a legislação não precisa ser efetiva, sendo suficiente que a criança ou adolescente acredite nessa possibilidade. Dessa forma, é crime um adulto conversar online com uma menina ou menino de 15 anos de idade se seu objetivo for: 1) convidá-la(o) para um encontro sexual; ; ou 2) se a pessoa convence a criança ou adolescente de que o convite é verdadeiro, mesmo não existindo a efetiva intenção de concretizar o encontro. Se a intenção é a produção da pornografia infantil, a proibição da comunicação sobe para 18 anos. Como afirma Suzanne Ost (2009, 90), ao mirar no assédio/ grooming, a legislação não criminaliza comportamentos que causam danos em si, mas comportamentos que poderiam levar ao dano, ou seja, "o dano do assédio/ grooming foi construído como dano potencial ou antecipado".

Em 1940, no Brasil, um novo Código Penal foi escrito em substituição a outro mais antigo, de 1890. Na versão de 1940, foi definido o crime de sedução. $\mathrm{O}$ artigo 217 proibiu a sedução de mulher virgem, entre 14 e 18 anos de idade, com o objetivo de com ela manter relações sexuais, aproveitando-se de sua inexperiência ou confiança. Os valores que justificaram esse hoje considerado ultrapassado crime são: virgindade era um valor que deveria ser mantido até o casamento; jovens mulheres eram consideradas ingênuas e vulneráveis, fáceis de serem enganadas pelos homens. Discutindo o crime de sedução, Abreu (2000) e Bessa (1994) demonstraram o papel da justiça em organizar comportamentos sexuais e papéis de gênero, Bessa inclusive argumentando que o sistema de justiça teve o papel de construir subjetividades sexualizadas. Ainda que bastante diferentes nos valores que justificam sua criminalização, tanto o crime de sedução quanto o de assédio/ grooming online apontam para o processo que precede e possibilita uma relação sexual ou sexualizada. Ambos possuem como justificativa a compreensão de que as vítimas - a jovem mulher, no primeiro caso, crianças e adolescentes, no

7 A idade de consentimento adotada pela legislação canadense, de 14 anos até 2007, passou então para 16 anos (ver discussão na próxima sessão deste texto). Dessa forma, qualquer relação sexual com menores de 16 anos (desde beijos e carícias até intercurso sexual) é, atualmente, proibida. Algumas exceções: 1) pessoas com 14 ou 15 anos podem consentir com a atividade sexual desde que a diferença de idade do(a) parceiro(a) seja de menos de 5 anos e não exista nenhuma relação de confiança, autoridade, dependência ou qualquer outra forma de exploração; 2) pessoas com 12 ou 13 anos podem consentir com a atividade sexual desde que a diferença de idade do(a) parceiro(a) seja de menos de 2 anos e não exista nenhuma relação de confiança, autoridade, dependência ou qualquer outra forma de exploração (conforme Código Criminal, Artigo 150.1). 
segundo - são vulneráveis e necessitam de proteção. Os valores que justificam o crime de assédio/ grooming online serão discutidos na próxima sessão.

\section{Por que a necessidade de uma nova lei? Representações de assédio/grooming online nos debates Parlamentares e na mídia}

A proposta de uma nova lei sobre assédio sexual no Canadá veio como uma reação a uma decisão da Suprema Corte sobre pornografia infantil, o caso Robin Sharpe. Robin Sharpe foi processado por pornografia infantil após a apreensão de um texto intitulado Sam Paloc's Boyabuse - flogging, fun and fortitude: a collection of Kiddiekind classics, e de uma coleção de livros, manuscritos, estórias e fotografias alegadamente contendo pornografia infantil (Akdeniz, 2008: 143). Ao longo do processo criminal (julgamento, apelo e novo julgamento), a legislação Canadense foi desafiada e, em primeiro julgamento, a proibição da posse de pornografia infantil foi considerada inconstitucional. O que estava em jogo durante o longo processo criminal era a disputa entre dois princípios, a liberdade de expressão e a proteção de crianças.

O Parlamento Canadense reagiu ao caso Sharper introduzindo a Bill C-15A, uma proposta de emenda do código criminal e de emenda a outros atos ou leis criminais, 2001. A Bill C-15A indicou emendas às regras existentes sobre pornografia infantil, propondo a criminalização do acesso à pornografia infantil e, também, a criminalização do assédio sexual. A aprovação pelo Parlamento ocorreu em junho de 2002 (Akdeniz, 2008: 150).

Ao introduzir o debate em primeira leitura do Projeto de Lei C-15A, o Senador Landon Pearson (2001: 1609) lembrou a todos que as provisões dessa proposta respondiam ao compromisso assumido pelo Governo do Canadá, após a última eleição, de "proteger as crianças daqueles que abusam de sua vulnerabilidade" e à chamada, por parte do Ministro da Justiça, de criação do crime de assédio sexual online. Apesar de lembrar pontos positivos da Internet, afirmou que ele, assim como

a maior parte dos cidadãos gostariam de prevenir o uso da Internet por pessoas que, da segurança e privacidade de suas próprias casas, se utilizam do anonimato propiciado pelo ambiente online para ludibriar crianças a situações em que pudessem ser sexualmente exploradas (Pearson, 2001: 1609).

Essa nova ofensa criminal, o assédio sexual, responderia, segundo o Senador Pearson, a um problema reportado pela polícia e pela mídia como um fenômeno crescente (Pearson, 2001: 1609). Tanto os membros do Parlamento quanto 
os especialistas chamados a testemunhar durante o debate concordaram que 0 assédio sexual era um fenômeno crescente (Grecco, 2015: 140-141). ${ }^{8}$ Reivindicações como a de que "com o rápido crescimento da Internet uma enormidade de crianças estava sendo inadvertidamente sugadas por armadilhas colocadas por pedófilos" (Stoffer, 2001: 5353 citado por Greco, 2015: 136) foram ouvidas durante os debates.

A preocupação de que a lei proposta teria alcance limitado e, portanto, de que mais deveria ser feito em nome da proteção às crianças, foi expressa ao longo do processo de aprovação da legislação sobre assédio sexual, apontando para a necessidade do aumento da idade de consentimento, que naquele momento era de 14 anos (Owen, 2001: 6312; Pearson, 2001: 1609; Toews, 2001: 6314).

Ao falar sobre a necessidade de aumento da idade de consentimento, Blaikie (2001: 6316) ponderou que a justificativa para tanto não estava em proibir jovens de terem relações sexuais, mas, sim, de terem relações sexuais com pessoas mais velhas:

Nós temos esse buraco na legislação que permite a uma pessoa de 40 anos explorar jovens de 14 anos ou mais na Internet, pois não temos uma lei adequada às circunstâncias que podem agora ocorrer na Internet. Temos que fazer isso com sensibilidade pois não queremos criminalizar certos comportamentos, particularmente entre adolescentes com idade próxima. É preciso haver uma forma de olhar para essa questão com sensibilidade, mas ainda assim leis precisam ser criadas a fim de prevenir ou ao menos punir esse tipo de atividade.

Em 2007, a aprovação do projeto da Bill C-22: Uma proposta de emenda do Código Criminal (idade de proteção) e emendas relacionadas no Ato de Registros

8 Em sua tese de doutorado, Christopher Grecco (2015) discutiu e retrabalhou o conceito de pânico moral utilizando a discussão parlamentar sobre assédio sexual online como estudo de caso. As citações que faço de seu trabalho estão restritas às ricas descrições dos debates parlamentares em torno da aprovação da Seção 172.1 do Código Criminal Canadense.

9 O uso das palavras pedofilia ou pedófilo, geralmente, é feito de forma desconectada de sua definição médica (ver Nota 2 deste texto), adquirindo um significado pejorativo ou apelativo. O pedófilo é frequentemente identificado como o "bicho papão" (Silverman; Wilson, 2002) ou "monstro" contemporâneo (Lowenkron, 2013). No Canadá, como mostrado nesta sessão do texto, o uso das palavras pedófilo e pedofilia esteve presente nos discursos no espaço legislativo. Em comparação com o Brasil, contudo - e aqui levanto apenas uma problematização -, esse uso não me parecer ser tão disseminado. Em nosso país há, inclusive, a denominada "cruzada anti-pedofilia", buscando sua criminalização (Lowenkron, 2015; Rodrigues, 2017). Não há espaço neste texto para proceder a essa discussão, mas deixo indicada a importância, na sequência dos estudos de Lowenkron e Rodrigues, de aprofundar a discussão sobre o significado jurídico da tentativa de criminalização da pedofilia no Brazil. 
(2007), elevou a idade de consentimento de 14 para 16 anos. Ao longo das audições desse projeto de lei, houve uma preferência por exemplos anedóticos em detrimento de evidências empíricas. Assim, ao falar sobre os perigos de adolescentes interagirem com adultos, foram utilizados exemplos em que $o$ adulto tinha 35, 40 ou 55 anos, não tendo sido discutidos dados sobre a prevalência efetiva de homens dessa faixa etária interagindo com adolescentes, ou mesmo relatórios que permitissem analisar a idade de parceiros sexuais (Dauda, 2010: 173).

A aprovação da elevação da idade de consentimento de 14 para 16 anos ampliou o escopo da legislação sobre assédio online. Soma-se a isso um aumento também da pena de prisão (mínima e máxima) em caso de assédio online. ${ }^{10}$ Estudar os valores implícitos no processo de criminalização do assédio torna-se, então, ainda mais significativo, pois, se o olhar está sendo direcionado para a representação do assédio sexual online, e, portanto, para o que uma sociedade reputa como violência, a aprovação dessas propostas - no sentido de agravar a pena ou escopo do Artigo 172.1 - indicam a forte repulsa social à ideia de que a Internet possa ser utilizada para a sedução de crianças e adolescentes. As afirmações e reivindicações expostas durante os debates Parlamentares, entendidas como representações de assédio sexual, de possíveis vítimas (as crianças) e possíveis agressores, nos dão indicativos dos medos e valores sociais em questão, os quais justificavam a necessidade de uma nova lei.

Reivindicações similares - e representações similares - podem ser encontradas na mídia canadense. De acordo com Greco e Corriveau (2014), em três dos jornais mais lidos de Toronto para os anos 1998 a 2008, o assédio sexual online foi retratado como uma ameaça constante, assim como uma catástrofe que deveria ser enfrentada pela sociedade. A ideia de que pedófilos poderiam, com a ajuda da Internet, entrar nos espaços sagrados das casas estava presente nos jornais. Três características das tecnologias da informação e da comunicação foram apresentadas como justificativa para o aumento perceptível dessa nova ameaça, as quais facilitariam ou acentuariam o problema da agressão sexual contra crianças: 1) o fato de a Internet poder ser utilizada como meio de contato por um número incalculável de pessoas, bem como uma plataforma para encontrar diferentes conteúdos e materiais; 2) a falta de fronteiras geográficas, o que dificulta o policiamento e permite maior acessibilidade; 3) a Internet poderia produzir um sentimento de anonimato entre os usuários, facilitando a execução de crimes nesse ambiente.

10 Esse aumento de pena é resultante da Bill C-277, An Act to amend the Criminal Code (luring a child), a qual recebeu assento real no Parlamento em 2007. 
A teoria do pânico moral foi formulada no fim dos anos 1960 e início dos anos 1970, tendo Stanley Cohen ([1972] 2011) e Jock Young (1971) como principais formuladores. De forma breve e simplificada, o pânico moral é entendido como uma reação exagerada a algum evento, esporádico ou sistemático, retirando o foco tradicionalmente dirigido ao desviante e suas características e direcionando a análise à reação, adquirindo a mídia papel central no processo.

Seguindo a linha de discussão do pânico moral, Roger N. Lancaster (2011) fala sobre pânico sexual. A noção de pânico sexual é então relacionada ao Estado Punitivo, à ideia de que a criminalidade pode ser resolvida por mais punições e punições mais duras, em detrimento de alternativas. ${ }^{11}$ Greco e Corriveau (2014), já mencionados anteriormente, levantam a hipótese de que as representações de assédio sexual encontradas nos jornais canadenses ajudaram a gerar um pânico moral, possibilitando intervenções legislativas ou "pânicos legislativos". A dificuldade é, obviamente, traçar uma correlação efetiva entre as notícias publicadas nos jornais e a intervenção legislativa, ficando a discussão no patamar de hipótese.

Distanciando-me da discussão que busca provar ou discutir a relação efetiva entre as representações de assédio sexual presentes na mídia e a aprovação da legislação a esse respeito, retomo a discussão dos valores (explícitos ou implícitos) que dão sentido à discussão sobre assédio sexual, e, portanto, à discussão sobre moralidade. O pânico moral, como o vê Young (2011), constitui um "conflito moral entre autoridade e subcultura". Garland (2008: 11) lembra dois elementos essenciais à definição de Cohen de pânico moral, que merecem registro aqui: a dimensão moral da reação social e a ideia de que a conduta desviante em questão é, de alguma forma, sintomática.

Gayle Rubin (1984) entende pânicos morais como "momentos políticos" do sexo, permitindo o redesenho de limites aceitáveis e das políticas e legislações que regrarão efetivamente a prática em questão. E a rapidez com que pânicos morais se sucedem na sociedade contemporânea, como nos lembra Miskolci (2007, 114-115), deve-se à necessidade de debater e renegociar constantemente os limites morais da coletividade, os quais não são mais redutíveis a um conjunto de regras simples pronunciado por líderes religiosos ou políticos.

11 Um ótimo estudo de caso a respeito das consequências de um pânico moral pode ser encontrado em Critcher, 2002. Nesse texto, o autor analisa não apenas a proposta de lei denominada Sarah's Law como o ressurgimento de movimentos vigilantistas após o assassinato da pequena Sarah Payne, de 9 anos de idade, ocorrido na Inglaterra em julho de 2000. 
Para Garland (2008), pânicos morais podem referir-se tanto a casos específicos ${ }^{12}$ quanto a sequências mais amplas de casos, ${ }^{13}$ e os problemas sociais aos quais respondem podem ser sérios, triviais ou mesmo frutos da imaginação. Ao citar o exemplo do abuso sexual de crianças, afirma que o pânico moral pode servir para atrair a atenção e colocar a questão na agenda política. A seriedade do problema do abuso, contudo, seria suficiente para justificar as reações sociais subsequentes. O abuso, "como mostra Hacking (2000), tem sido sublinhado, conceitualizado e discutido nas últimas décadas. $\mathrm{O}$ acúmulo de reações sociais e governamentais à questão do abuso criou, em nossas sociedades, um regime completamente novo de suspeita, supervisão e controle" (Garland, 2008: 16).

A discussão sobre assédio sexual online feita neste texto não se restringe a um ou outro caso específico, pois trata-se de um problema social amplo e sério. Seguindo Garland, entendo que um certo nível de pânico moral contribuiu para que o tema fosse colocado na agenda política e a legislação fosse aprovada. Contudo, há uma questão subjacente que deve ser explicitada: o estabelecimento de uma legislação acerca do assédio sexual online, aplicável apenas a menores de idade, tomada em conjunto com o aumento da idade de consentimento sexual, são fortes indicativos de que a criminalização do assédio sexual online esteve amparada por uma rediscussão dos limites morais que envolvem a sexualidade de crianças e adolescentes. Retomarei essa discussão ao final do texto, discutindo antes as representações de assédio sexual encontradas em processos judiciais.

\section{Crianças são inocentes e devem ser protegidas - representações em relatórios de cásos criminais ${ }^{14}$}

Em 2014, realizei uma pesquisa com base em casos criminais julgados por assédio sexual em Ontario, Canadá. Tendo duas bases de dados jurídicos como

12 No Brasil, o caso mais conhecido de um pânico moral em torno de um caso específico de abuso sexual é o da Escola Base. Esse é um dos casos analisados por Rodrigues (2017) como exemplo de pânico moral. O objetivo do autor, contudo, vai muito além, direcionando seu trabalho para a discussão da fabricação de subjetividades contemporâneas à luz de Michel Foucault e das narrativas da pedofilia.

Outro caso muito conhecido é o da McMartin Preschool, localizada em Mannhattan Beach (Los Angeles), cujo pânico girou em torno do possível abuso ritual de crianças que frequentavam aquela escola. A respeito desse caso, pelo menos três livros foram escritos, apresentando interpretações e análises muito diferentes: Nathan and Snedeker (1995); Cheit (2014) e Beck (2015).

13 Para uma discussão sobre possíveis pânicos morais mais amplos, ver Jenkins (2001 e 2009). A leitura desses textos é muito interessante, pois Jenkins revê sua posição inicial de que haveria um pânico moral a respeito da pornografia infantil na Internet, chegando a afirmar que esse é um dos temas que "falharam" em detonar um pânico moral.

14 Neste texto, lido apenas com representações acerca da vítima, ofensor e do próprio crime de assédio, não falo sobre os "relatos" ou "histórias" dos casos, do que se passou. Alguma menção a esse respeito pode ser encontrada em (Landini e Zeytounlian, 2018). Um texto com esse enfoque resta ainda por ser escrito. 
fonte, LexisNexis e Westlaw, ${ }^{15}$ tive acesso a 69 casos julgados entre 2002 (ano da inclusão do assédio sexual no Código Criminal) e 2014 (ano da coleta de dados), os quais foram inseridos em um banco de dados na plataforma NVivo.

Relatórios judiciais, os quais constituem um resumo dos autos de um processo judicial, possibilitam o acesso a dados legais. Ainda que a qualidade das informações encontradas nesses relatórios não seja homogênea, o material permite acessar dados importantes, como descrições do(a) acusado(a) e do(a)s reclamantes autore $(\mathrm{a}) \mathrm{s}^{16}$ de processos de assédio sexual, bem como das circunstâncias em que ocorreu o crime sob julgamento. Possibilita também o acesso à sentença e às justificativas da sentença proferida pelo juiz.

É indiscutível que a análise do material deve ser realizada com cuidado e considerando sua natureza e limites. Um relatório de julgamento - ou mesmo transcrições de processos criminais - não pode ser entendido como uma narrativa neutra da realidade empírica. Advogado(a)s de defesa e de acusação, além do(a) próprio(a) reclamante, do(a) acusado(a) e das testemunhas, proferem diferentes interpretações a respeito de um mesmo fato, resultando visões contraditórias a respeito da culpa, das efetivas ações dos envolvidos, diferentes justificativas para os atos etc.

Ainda que alguns números sejam apresentados, a análise do material foi qualitativa, consistindo na leitura densa dos documentos, procurando compreender a visão do juiz do caso no que diz respeito ao crime de assédio online, sua vítima e agressor. Mantendo a linha de discussão que adoto neste texto, utilizarei esse material como fonte de representações do assédio sexual, ou seja, uma forma de acessar os valores embutidos na compreensão do caso em questão. Mas, antes de adentrar essas representações, apresento um panorama geral dos casos analisados, apenas algumas quantificações para ajudar o leitor a se situar no universo do material empírico estudado. ${ }^{17}$

15 As plataformas LexisNexis e Westlaw possuem o maior arquivo de casos criminais julgados no Canadá, constituindo-se, portanto, em instrumentos apropriados para acesso a informações legais.

16 Nos relatórios judiciais, a palavra em inglês utilizada para fazer referência ao/ à criança ou adolescente é complainant, ou reclamante. Utilizo tanto a expressão "autor de processo de assédio" quanto "reclamante" para fazer referência à criança ou adolescente supostamente vítima de assédio sexual, evitando assim o uso da palavra "vítima". Essa escolha de terminologia possui duas justificativas: primeiro, porque em alguns casos o acusado foi inocentado das acusações e, portanto, a palavra vítima não seria adequada; e, segundo, porque alguns autores de processos judiciais ou reclamantes recusam a posição de "vítimas" de assédio, discussão que introduzo na seção final deste artigo.

17 Apesar de constituírem o maior arquivo de casos criminais julgados, nenhuma das plataformas utilizadas (LexisNexis e Westlaw) disponibiliza a totalidade dos julgamentos ocorridos e, portanto, não tenho qualquer pretensão de que esse cenário apresentado seja representativo dos crimes de assédio ocorridos no ambiente online, ou sequer de que sejam representativos de todos os casos julgados por assédio no Canadá ou em Ontário. 
Entre os 69 casos estudados, ${ }^{18} 36$ referem-se a investigações ativas (sting operations), enquanto os outros 33 casos tiveram um(a) menino(a) como reclamante da ação. Nas investigações ativas, um(a) policial assume a idade de um(a) criança/ adolescente menor de idade com o objetivo de buscar e atrair possíveis criminosos. ${ }^{19}$ Em relação ao gênero, 33 policias assumiram a identidade feminina e apenas 3 uma identidade masculina. Dos 36 casos, em 24 deles o policial afirmou ter menos de 14 anos e em 12 casos fez de conta que tinha entre 14 e 15 anos.

As pessoas denunciadas em função dessas operações policiais eram todas do sexo masculino. Em relação à idade, 4 tinham entre 19 e 30 anos, 10 tinham entre 31 e 40 anos, 9 tinham entre 41 e 50 anos, 4 entre 51 e 60 anos e 1 entre 61 e 70 anos. Em 8 casos, essa informação não estava disponível.

Em relação aos 33 casos que tinham uma menina ou menino reais como reclamantes do processo, ${ }^{20}$ a maior parte era de meninas ( 28 dos 33 casos). Nos quatro casos que tiveram um menino como reclamante, os acusados eram também do sexo masculino. As idades dos reclamantes variavam entre 12 e 17 anos, tendo a maioria entre 12 e 13 anos (14 dos 33 casos).

Os acusados eram quase que em sua totalidade do sexo masculino (32 dos 33). A única acusada do sexo feminino foi uma garota de 17 anos que coagiu outras garotas a fazerem programas sexuais. As idades dos acusados variaram dos 17 aos 70 anos, sendo a faixa dos 19 aos 25 anos a de maior concentração (8 dos 33).

Outra informação importante diz respeito à relação entre contatos online e offline. Entre os 33 casos que possuem uma menina ou menino reais como reclamantes, 8 referem-se a relações restritas ao ambiente online, 13 a relações em que acusado e reclamante conheceram-se online e continuaram o relacionamento offline (crimes sexuais iniciados pela Internet) e 12 a casos em que acusado e reclamante já se conheciam em pessoa e utilizaram o ambiente online para continuar ou incrementar a comunicação.

A partir da revisão bibliográfica a respeito do assédio sexual online, podemos estabelecer três discussões que aparecem de forma recorrente nessa bibliografia: as tecnologias da informação e da comunicação (TIC) facilitam o

18 O "caso", tal qual o trabalhei, é constituído por todos os julgamentos referentes a um mesmo possível crime, ou seja, quando um crime foi julgado em mais de uma instância, os julgamentos foram contabilizados como um único caso.

19 Esses números constituem, em si, um indicativo importante de que há uma grande preocupação das instâncias policiais com a possível ocorrência de assédios online a crianças e adolescentes. Dentre os artigos que discutem as investigações ativas, estão os de Briggs, Simon e Simonsen (2011); Chin (2006); Anglin (2002); Fulda (2002); Mitchell, Wolak e Finkelhor (2005). 
encontro de pessoas que não travariam conhecimento de outra forma; também abrem a possibilidade de que as pessoas criem um personagem fictício para si mesmas a fim de interagir com outras; e engendram a possibilidade de que as pessoas se sintam livres das coerções sociais e ajam de forma diferente do que fariam em interações físicas (Alexy; Burgess; Baker, 2005; Briggs; Simon; Simonsen, 2011; Lamb, 1998; Malesky Jr., 2007; Martellozzo, 2011; Shannon, 2008; Taylor, 2011; Quayle; Taylor, 2001; Davidson; Gottschalk, 2011).

Contudo, é importante apontar que, entre os 33 casos em que há reclamantes reais no processo judicial, apenas 3 dos acusados haviam criado um personagem mais elaborado e apenas um adulto apresentou-se como tendo menos de 18 anos. Outros 4 mentiram sobre sua idade, mas, de qualquer forma, apresentaram-se como maiores de idade. Outro adulto mentiu sobre sua idade, mas a revelou à reclamante ao longo do tempo em que se relacionaram. De forma geral, 9 das 33 pessoas acusadas de assédio sexual mentiram sobre suas idades durante o contato ou a relação com a criança/ adolescente. Da mesma forma, um número significativo de reclamantes também mentiu sobre sua idade. Ao todo, 8 reclamantes esconderam o fato de não terem atingido a idade de consentimento ou se apresentaram como mais velhos(as) do que efetivamente eram.

Em suma, casos julgados por assédio sexual online em cortes criminais de Ontário revelam variedades e diferenças em relação a: idades das criança/ adolescente e diferenças de idades entre crianças/ adolescentes e adultos; 0 uso ou não de mentiras de ambos os lados; o "local" em que se deu o relacionamento (online ou online/ offline); e as circunstâncias em que ambos travaram conhecimento inicial (online ou em pessoa). Mas, para além dessas diferenças, há o entendimento consensual - e aqui volto a discutir representações sociais - de que o assédio sexual é um crime muito sério que vitimiza não apenas a criança reclamante do processo, mas todas as crianças e a sociedade de forma geral. Cito alguns trechos dos relatórios: ${ }^{21}$

O crime de assédio sexual online é um crime da época moderna - nascido da moderna realidade da Internet, onde um acusado pode ter a intenção de atrair uma criança a tomar parte em uma atividade proibida dentro da santidade de sua própria casa. (R. v. Dobson, para 3)

Assédio sexual é um crime que machuca não apenas a criança vítima, mas a sociedade de forma geral. Em uma época em que predadores sexuais navegam pela Internet em busca de vítimas vulneráveis, os pais devem ser

21 Os trechos citados referem-se tanto a casos resultantes de investigações policiais ativas quanto aos que possuem uma criança/ adolescente real como reclamante. 
extra-vigilantes ao monitorar o uso do computador por parte de seus filhos, ensinando-os segurança no ambiente online e a necessidade de exercer cautela. Esse sentimento de medo e as razões para o medo não são saudáveis, ainda que necessários em uma sociedade para inculcar nas crianças o reconhecimento da necessidade de segurança pessoal. Qualquer pai ou mãe tem medo de que o que o Sr. X estava fazendo com a "Natasha", uma criança de 12 anos de idade, vá acontecer com seu(sua) filho(a). (R. v. Bergeron, para 27)

Em seu Artigo 718, o Código Criminal do Canadá define que "o propósito fundamental da sentença é a proteção da sociedade e a contribuição, junto com iniciativas de prevenção criminal, do respeito à lei e à manutenção de uma sociedade mais justa, pacífica e segura”. Ainda de acordo com o Artigo 718, esses propósitos são atingidos ao serem impostas "sanções justas" e que tenham um dos seguintes objetivos considerados: denúncia de uma conduta ilegal e dos danos causados às vítimas ou à comunidade; a dissuasão do ofensor e de outras pessoas de cometerem a ofensa; separar os ofensores da sociedade; auxiliar na reabilitação; proporcionar reparação; desenvolver senso de responsabilidade no ofensor.

Dentre esses objetivos, os mais citados nos casos analisados de assédio sexual são denúncia e dissuasão. Ter a denúncia como princípio da sentença é uma forma de expressar a desaprovação social ao crime cometido, é "menos sobre culpar um determinado ofensor e mais sobre definir os valores do código moral que esperamos que as pessoas adiram em nossa sociedade." Em relação à dissuasão, o pressuposto subjacente é que a "ameaça ou exemplo da punição irão desencorajar outras pessoas de cometerem o mesmo crime”. A dissuasão pode ser considerada em dois níveis, geral e específico, referindo-se ao uso de sentenças rigorosas a fim de desencorajar a sociedade em geral (possíveis ofensores) de cometer uma determinada ofensa, além de dissuadir o próprio ofensor de repetir o mesmo crime. ${ }^{22}$

Esses princípios estão muito claros na maioria dos casos analisados e revelam a tentativa do juiz de enfatizar sua desaprovação em relação ao assédio sexual online:

Uma mensagem precisa ser enviada a outros que considerem a execução de atos similares aos do acusado. (R. v. Blanchard, para 40)

Precisamos enviar uma mensagem a todos os adultos que buscam explorar jovens mulheres impressionáveis e imaturas a fim de satisfazer suas

22 Disponível em: <http://www.lawconnection.ca/content/sentencing-theory-backgrounder>. Acessado em: 02 ago. 2018. 
necessidades sexuais de que o tribunal julgará essa conduta de forma bastante severa (R. v. Johnston, 2009, para 83).

(...) assédio sexual via Internet é algo muito sério e pede denúncia pesada. A comunidade deve ser assegurada de que a administração da justiça agirá com força na proteção de crianças e será severa com aqueles que não respeitarem as normas. Aqueles que usam a Internet para entrar em contato com crianças tendo como objetivo cometer uma das ofensas citadas na legislação, devem saber que serão julgados severamente. (R. v. Brown, para 116)

Esses princípios de denúncia e dissuasão são importantes para os propósitos deste texto, pois revelam o peso atribuído pela justiça criminal à proteção das crianças e adolescentes. Em outras palavras, o valor moral de que crianças e adolescentes devem ser protegidos de qualquer ofensa sexual é muito presente nos casos criminais e os juízes não hesitam em deixar isso claro ao passarem ou justificarem uma sentença:

Valor sagrado de virtualmente toda sociedade no mundo é a necessidade de proteger a inocência de nossas crianças. Isso reflete um reconhecimento internacional de que as crianças são excepcionalmente vulneráveis a transgressões de pessoas mais velhas que vivem suas vidas sem escrúpulos (R. v. Bedford, 2008, para 2).

As vítimas eram vulneráveis por serem crianças. Crianças devem ser protegidas e alimentadas. Interferir com uma criança ou sua família é uma questão séria (R. v. Brown, 2006, para 97).

Um detalhe para o qual gostaria de chamar a atenção é que, em alguns casos, o direito ou necessidade de proteção do(a) criança/ adolescente é reconhecido a despeito do entendimento do próprio juiz de que ele/ ela tenha participado ativamente da relação sexual ou sexualizada. Nesses casos, podemos falar em vítima estatutária (Wolak, Finkelhor; Mitchell, 2004), definida como um(a) menino(a) que foi participante ativo de uma relação, mas que ainda não tinha atingido a idade legal de consentimento.

BW não foi um inocente completo. De fato, estava longe disso. Ainda assim, ele é um jovem com direito à proteção da lei e do tribunal. Percebo que sua recusa em participar da acusação de Mr. Bridgeman inclui a recusa de preencher a Declaração de Impacto sobre a Vítima. Aceito que, no curto prazo, ele tenha sofrido tanto por ser condenado ao ostracismo em função de seu envolvimento com fetiches sexuais com um homem mais velho, bem 
como por ser uma vítima do Sr. Bridgeman. Mas isso não significa que ele não tenha sido vítima de tal exploração" (Bridgeman, 2011, para 105-106) ${ }^{23}$. "H. e A. eram ambas participantes ativas na atividade sexual. Entretanto, como ambas tinham menos de dezesseis anos de idade naquele momento, não poderiam consentir com a atividade sexual. (R. v. Saliba, para 18$)^{24}$

Em suma, a despeito das especificidades de cada um dos 69 relatórios criminais de assédio sexual analisados, a mensagem geral é de que o assédio sexual é um crime muito sério, que crianças/ adolescentes são inocentes e vulneráveis e, por essa razão, devem ser protegidos nas interações online com adultos, seguindo, portanto, a linha argumentativa da lei proposta pelo Parlamento e das discussões ali ocorridas, bem como das notícias reportadas por jornais impressos. Afirmar que um(a) adolescente é vítima de assédio sexual mesmo sendo um participante ativo do processo apenas reforça a ideia de que crianças e adolescentes são inerentemente vulneráveis e devem ser protegidos, a despeito de suas ações ou desejos.

\section{Comentários finais}

Katie.com é um livro auto-biográfico escrito por Katherine Tarbox (2001). Em 1995, quando tinha apenas 13 anos de idade, ela conheceu um rapaz em uma sala de chat na Internet e se apaixonou. Em um primeiro momento, ele lhe disse que tinha 23 anos, depois, que tinha 31. Na realidade, ele tinha 41 anos de idade. Eles conversaram via Internet por 6 meses, até que ela concordou em

23 O caso refere-se a um homem de 52 anos de idade, previamente condenado por crimes sexuais, que conheceu um garoto de 14 anos em uma sala de bate-papo. Eles se encontraram algumas vezes e tiveram relações sexuais. De acordo com os relatórios judiciais, o acusado acreditava que o menino tinha 17 anos. A redação dada ao Artigo 172.1 do Código Criminal diz que é proibido comunicar-se com uma pessoa que seja, ou que o acredita-se ser, menor de 18, 16 ou 14 anos para os fins definidos. Ou seja, não pode ser declarado culpado aquele que se comunica com um garoto que acreditava ter 17 anos para ter relações sexuais, já que a idade de consentimento é 16 anos. Dessa forma, ele foi inocentado da acusação de assédio sexual com fins de abuso sexual. Entretanto, como a relação sexual foi filmada e a pornografia infantil é proibida até os 18 anos, ele foi condenado pelo crime de assédio sexual com objetivo de cometer pornografia infantil.

24 No caso em questão, um homem de 38 anos foi acusado de se relacionar com duas garotas no ambiente online e encontrá-las para ter relações sexuais. Com ele, foi encontrado material caracterizado como pornografia infantil e descrito como "particularmente torpe e envolvendo a vitimização de diversas crianças pequenas". Em ambos os casos, as histórias são similares. Ele conheceu cada uma das meninas na Internet, propôs um encontro presencial logo em seguida e desenvolveu um relacionamento com cada uma delas - o relacionamento durou 9 meses com a primeira e, após o rompimento, um relacionamento de 2 meses com a outra. Ambas as meninas disseram a ele que tinham 18 anos, mas tinham 14 e 15 anos. $\mathrm{O}$ juiz do caso afirmou que ambas foram participantes ativas na relação, ainda que não pudessem consentir livremente com a relação sexual por serem menores de 16 anos. 
encontrá-lo em pessoa. Ela morava com a família em Connecticut e ele vivia na Califórnia. Uma viagem ao Texas para tomar parte em uma competição de natação - ela era vista como uma nadadora promissora! - foi a oportunidade para que eles se encontrassem. Ele pegou um avião para Dallas e reservou um quarto no mesmo hotel em que a equipe de natação estaria hospedada. À noite, ela foi até o quarto dele.

Isso tudo aconteceu em 1995, quando a Internet ainda engatinhava e as salas de bate papo online estavam começando a ser usadas para a socialização juvenil. O homem que se comunicou com Katie tornou-se o primeiro a ser processado por pedofilia via Internet. Além de escrever esse livro autobiográfico, Katie Tarbox tornou-se uma militante pelos direitos das crianças, proferindo palestras em escolas para falar sobre os perigos da Internet.

Em seu livro, Katie oferece seu testemunho de como foi difícil para ela construir e aceitar o status de vítima - vítima de assédio sexual online, da sedução de um homem que pretendia abusar sexualmente dela. Ela achava que sabia o que estava fazendo, ela se via como uma participante ativa na relação, uma garota que se apaixonou e que queria construir uma relação amorosa com o sujeito. Aceitar e entender que, ao contrário, ela havia sido seduzida para o abuso foi um processo doloroso para ela, como afirma no livro.

Em paralelo e complementando seu processo individual, as pessoas pertencentes a seu grupo social também mudaram sua visão a respeito do que havia acontecido com (ou contra) ela. No início, família, amigos e comunidade a haviam culpado pelo ocorrido, ela não havia sido vista como vítima. Apesar de seus 13 anos de idade, havia sido culpabilizada por socializar-se com ele na Internet e por ter ido a seu quarto de hotel à noite. Após ter sido vista primeiramente como puta, passou, em seguida, a ser vista como a garota que foi violentada.

O momento em que isso tudo ocorreu - 1995 - é importante. Com a massificação da Internet, os crimes sexuais online passaram a ser mais debatidos e reportados pela mídia de massa, trazendo novas informações e visões. Como mostrado nas sessões anteriores, além de avanços positivos, a Internet foi (e ainda é) vista como um buraco negro, um espaço sem leis e sem fronteira, no qual crianças e adolescentes poderiam (podem) ser facilmente vitimizados por adultos inescrupulosos e pedófilos que poderiam (podem) fazer uso do anonimato para seduzi-las a participar de fotos/ filmes de pornografia infantil ou, ainda pior, de encontros físicos. Esse é o terceiro nível do processo, um processo social em que a comunicação via Internet foi criminalizada como assédio sexual online e a "criança" em questão tornou-se vítima em termos jurídicos. 
Eliacheff e Larivière (2012: 27) nos lembram que vítima é uma figura contemporânea, pouco tendo sido dito a esse respeito antes da década de 1980 (ver também Sarti, 2011). Ainda que todos estejam sujeitos a se tornarem vítimas em algum momento de suas vidas, com liberdade para se agrupar em torno de uma identidade e requerer o status de vítima, de outros diz-se que são vítimas em função de sua condição. Crianças e adolescentes são um desses grupos. Paradoxalmente ao reconhecimento da criança e do adolescente como seres humanos com direitos e voz, são vistas hoje em dia como "vulneráveis como nunca o foram, vítimas potenciais de todos os tipos de perigo, pelo simples fato de serem crianças" (Eliacheff; Larivière, 2012: 91).

O desenvolvimento social de longo prazo é, do ponto de vista de Norbert Elias (2000), em grande parte não planejado. Isso significa que seria incorreto tentar explicar os processos sociais de longo prazo simplesmente em função de ações e planos intencionais, mas também significa que ações e planos intencionais possuem seu lugar nos processos sociais cegos. Assim, de acordo com Elias (1997:360), as estruturas e processos sociais emergem de um entrelaçar de ações e planos de muitas pessoas, mas o processo não deriva de nenhuma ação ou plano específico. Ao longo da história, contudo, algumas pessoas ou grupos tentaram intencionalmente transformar o comportamento de outros, usualmente na direção de padrões "mais civilizados". Quando esse esforço envolve uma campanha mais ou menos orquestrada, é possível falar em uma ofensiva civilizatória (Spierenburg, 2001: 98).

O processo de criminalização do assédio sexual online pode ser visto como uma ofensiva civilizatória, uma campanha que teve como objetivo administrar as relações online - especificamente aquelas entre adultos e crianças - a um nível mais aceitável. Sem dúvida, esse não foi um esforço isolado, na mesma direção há ofensivas civilizatórias em direção a uma maior equidade de gênero e outras de proteção a crianças e adolescentes. Ao longo dos últimos séculos, nossa sensibilidade em relação à violência sexual aumentou enormemente (Vigarello, 1998; Landini, 2005). Como Vigarello afirma de forma clara, ao final de seu livro, a violência sexual contra crianças tornou-se a violência de nosso tempo. Não porque tenha aumentado quantitativamente, mas porque nossos olhares estão direcionados a ela. Todas as formas de violência sexual contra crianças e adolescentes tornaram-se inaceitáveis e insuportáveis para nós, indivíduos do Século XXI.

A criminalização de ações ou comportamentos específicos é parte desse processo. $\mathrm{O}$ amplo uso da Internet e outras tecnologias da informação e da comunicação trouxeram à luz dois problemas sociais já conhecidos, mas que até 
então não geravam muita preocupação. A pornografia infantil foi o primeiro desses problemas a ser globalmente discutido e nacionalmente criminalizado - a maior parte dos países aprovou leis a esse respeito no fim da década de 1980 e início da década de 1990 (Landini, 2004a e b). A criminalização do assédio sexual online veio pouco depois, no fim da década de 1990 e início dos anos 2000 - ainda que a legislação a esse respeito não tenha (ainda) sido adotada por um número muito grande de países, o fato de o assédio sexual constar da Convenção pela Proteção de Crianças contra a Exploração e o Abuso Sexual do Conselho da Europa ${ }^{25}$ (2007), e de recomendações do UN Special Rapporteur on the sale of children, child prostitution and child pornography, incentivando os Estados Membros a introduzirem legislação criando a ofensa de internet luring ou grooming, aponta nessa direção.

Ao discorrer sobre as mudanças nas relações entre pais e filhos, Elias (2012) afirma que o "descobrimento da crianç" ${ }^{26}$ e "Ano da Criança"27 são signos de uma mudança nas balanças de poder entre pais e filhos, em favor de uma distribuição mais equilibrada do que em épocas anteriores. Da mesma forma, a criminalização de um ato agora denominado pelo Código Criminal como assédio sexual online (online luring) é também evidência do aumento de sensibilidade em relação à violência sexual e, em especial, à violência sexual contra crianças e adolescentes, ${ }^{28} \mathrm{o}$ qual constitui, nos termos eliasinos, um dos direcionamentos do processo de desenvolvimento social (ou processo civilizatório).

Se utilizei o conceito de representação ao longo deste texto, foi como forma de encontrar evidências dos valores morais que dão sustentação a esse processo de aumento da sensibilidade em relação à violência sexual contra crianças e adolescentes - processo mais longo e de maior espectro do que o processo de criminalização do assédio sexual, mas no qual este encontra-se inserido. Houve, efetivamente, um esforço articulado no sentido de criminalizar o assédio sexual, e não é por outro motivo que chamei esse processo de ofensiva civilizatória.

25 Artigo 23. ${ }^{\circ}$ - Abordagem de crianças para fins sexuais "Cada Parte toma as necessárias medidas legislativas ou outras para qualificar como infracção penal o facto de um adulto propor de forma dolosa, através de tecnologias de informação e comunicação, um encontro a uma criança que não tenha atingido a idade estabelecida em aplicação do $n .^{\circ} 2$ do artigo $18 .^{\circ}$, com a finalidade de cometer nesse encontro qualquer uma das infracções estabelecidas em conformidade com a alínea a) do $n .{ }^{\circ} 1$ do artigo $18 .{ }^{\circ}$ ou com a alínea a) do . $^{\circ} 1$ do artigo $20 .^{\circ}$, desde que essa proposta seja seguida de actos materiais que visem a tal encontro." https://rm.coe.int/CoERMPublicCommonSearchServices/DisplayDCTMContent?documentId=09 oooo168046e1d8, acessado em abril;2017.

26 Como discutido por Ariès (1981).

27 Proclamado e celebrado pela ONU em 1979.

Aproprio-me aqui da discussão de Vigarello (1998), à qual já fiz referência mais acima. 
Contudo, é importante registrar que esse processo ou ofensiva não ocorreu de forma desarticulada de processos mais amplos, tendo se sustentado nos valores que estão explicitados em representações na mídia, nas falas dos políticos e também dos membros do poder judiciário, quais sejam: a representação da criança e do adolescente como inocentes, vulneráveis e com necessidade premente de proteção; o adulto, entendido como potencialmente perigoso, principalmente o pedófilo; e a Internet, entendida como um espaço difícil de ser policiado e que possibilita a manipulação de crianças e adolescentes inocentes e vulneráveis por adultos inescrupulosos. Além disso, constituem evidências que apontam na direção de uma rediscussão moral relativa à sexualidade de crianças e adolescentes: o aumento da idade de consentimento sexual, ocorrido poucos anos após a aprovação da lei sobre assédio online; o percentual de investigações policiais ativas em relação aos processos resultantes de um crime no qual há um autor/ vítima reais; e a discussão sobre a legislação constituir uma forma de denúncia e dissuasão de crimes contra a inocência e a vulnerabilidade inerentes a crianças e adolescentes.

Retomando a explicação do início do texto, entende-se o assédio sexual como um crime em que o dano é construído como um dano potencial. Ao criminalizar o assédio online, objetivava-se coibir a possibilidade de uma violência efetiva - quiçá podemos até dizer que objetivava-se alcançar a prevenção de crimes como o abuso sexual, a pornografia infantil etc. Ao enunciar o veredito de um dos primeiros casos de assédio sexual a chegarem à Suprema Corte do Canadá, o Ministro do Supremo Justice Fisher enfatizou essa questão. Segundo ele, o Artigo 172.1 do Código Criminal do Canadá (online luring):

(...) cria uma ofensa incipiente ou rudimentar, ou seja, um crime preparatório que mira em condutas que, de outra forma, seriam consideradas legais e que tenham como objetivo culminar em um crime completo. Criminaliza condutas que precedem a comissão de uma violência sexual à qual se refere, e mesmo uma tentativa de cometê-lo. Com efeito, não é preciso que o ofensor se encontre ou planeje encontrar-se com a vítima com o objetivo de cometer qualquer uma das ofensas secundárias. É assim para que seja possível alcançar o objetivo previsto pelo Parlamento Canadense de fechar as portas do cyber espaço antes que o predador encontre sua presa (R. v. Legare, 2009, at para 25 , itálicos da autora).

A frase "fechar as portas do cyber-espaço antes que o predador encontre sua presa", utilizada por um Ministro da Suprema Corte, além de tentar traduzir o 
objetivo da legislação sobre assédio sexual, é também bastante apelativa. Para além do fato de o assédio poder, sim, trazer dano à criança e ao adolescente danos efetivos e não apenas potenciais -, a formulação assusta de tão estereotipada que é. E assusta também em sua solução - diria radial e pretenciosa - de criminalizar a comunicação a fim de prevenir violências sexuais físicas ou que envolvam a imagem. $\mathrm{O}$ fato de mais da metade dos processos julgados em Ontário num período de 12 anos serem decorrentes de investigações ativas em que um(a) policial apresenta-se como criança ou adolescente no ambiente online a fim de ser "seduzido(a)" por um predador, "fisgando-o e trazendo-o aos braços da lei", fortalece o argumento: o foco é identificar possíveis abusadores sexuais e tirá-los de circulação antes que "entrem em ação", antes que ocorra o crime.

Em outros momentos (Landini, 2004a; 2004b), já iniciei a discussão a respeito da complexidade que envolve a circulação da pornografia infantil na Internet, a qual retomo para a discussão sobre assédio sexual online. O problema da pornografia infantil na Internet envolve uma questão muito mais complexa do que a pedofilia, e é tão mais complexa porque envolve um valor cultural: a valorização da sexualidade adolescente. Tanto em nível social quanto cultural, costuma-se ignorar o fato de que, ao mesmo tempo em que avançam os direitos da criança e do adolescente e que a sociedade se torna mais consciente da necessidade da proteção à infância, a sexualidade adolescente é também cada vez mais valorizada. Ou seja, ao mesmo tempo em que o tema da pedofilia e da violência sexual são cada vez mais entendidos enquanto problemas sociais sérios, há uma sexualização da imagem da criança e do adolescente. O corpo jovem é, ao mesmo tempo, valorizado e, cada vez mais, interdito (2004a).

Em relação ao assédio sexual, há uma questão suplementar que torna a equação ainda mais complexa. Nesse sentido, chamo a atenção para a importância em discutir mais amplamente a dinâmica online e as interações entre os envolvidos, questão que passou ao largo durante o processo de criminalização do assédio sexual. Sociabilidade, sexualidade e condutas criminais estão todas entrecruzadas no ambiente online. A Internet é um meio muito utilizado para sociabilidade por crianças e adolescentes, inclusive para estabelecer relações que são, senão sexuais, ao menos "sexualizadas" em sua natureza, tanto com pessoas conhecidas quanto desconhecidas, algumas vezes até com adultos. $\mathrm{Ou}$ seja, relações que, ainda que não cheguem ao ato sexual físico, possuem uma miríade de questões relacionadas (como a troca de fotografias, masturbação em frente à webcam, uma transa online etc.) que fazem dessa sociabilidade uma forma de violência aos olhos da lei. Ignorar esse cenário e insistir em construir e reconstruir a imagem da criança e do adolescente como vulneráveis e 
necessitando de proteção, e do adulto como potencial ofensor, é uma simplificação absurda. $O$ problema do assédio existe e é bastante sério em muitos casos, mas ter estereótipos como pilares que sustentam a legislação torna seu alcance e efetividade bastante limitados, demonstrando, claramente, que a legislação diz respeito não apenas à prevenção e punição de casos de violência, mas constitui também uma forma de rediscussão dos limites morais que envolvem a sexualidade de crianças e adolescentes.

\section{Referências}

ABREU, Martha. Meninas perdidas. In: DEL PRIORE, Mary (org). História das crianças nos Brasil. São Paulo: Contexto, 2000.

AKDENIZ, Yaman. Internet child pornography and the law: national and international responses. Barlington, USA: Ashgate Publishing Company, 2008.

ALEXY, Eileen M.; BURGESS, Ann W.; BAKER, Timothy. Internet offenders - traders, travelers, and combination trader-travelers. Jounal of Interpersonal Violence, v. 20, n. 7, 2005.

ANGLIN, Howard. The potential liability of federal Law-enforcement agents engaged in undercover child pornography investigations. New York University Law Review, v. 77,2002 , p. 1090-1117.

ARIÈS, Philippe. História Social da Criança e da Família. Rio de Janeiro: Zahar editores, 1981.

BECK, Richard. We believe the children - a moral panic in the 1980s. New York: Public Affairs, 2015.

BESSA, Karla. O Crime de Sedução e as Relações de Gênero. Cadernos Pagu. Campinas, v. 2, 1994, p. 175-196.

BRIGGS, Peter; SIMON, Walter T.; SIMONSEN, Stacy. An exploratory study of Internetiniciated sexual offenses and the chat room sex offender: has the Internet enabled a new typology of sex offender? Sexual Abuse: a journal of research and treatment. 23(1), 2011, p. 72-91.

CHEIT, Ross R. The Witch Hunt Narrative: politics, psychology, and the sexual abuse of children. Oxford, UK: Oxford University Press, 2014.

CHIN, Gabriel J. The story of Jacobson v United States: catching criminals or creating crime? Arizona Legal Studies, Discussion paper 06-12, 2006.

COHEN, Stanley. Folk Devils and Moral Panics - the creation of the mods and rockers. London and New York: Routledge Classics, 2011.

CRITCHER, Chas. Media, Government and Moral Panic: The politics of paedophilia in Britain 2000-1. Journalism Studies, 3(4), 2002, p. 521-535. 
DAUDA, Carol. Sex, Gender, and Generation: Age of Consent and Moral Regulation in Canada. Politics \& Policy, v. 38, n. 6, 2010, p. 1159-1185.

DAVIDSON, Julia; GOTTSCHALK, Petter (editors). Internet child abuse: current research and policy. Osfordshire: Routledge, 2011.

DAVIDSON, Julia. Legislation and policy: protecting young people, sentencing and managing Internet sex offenders. In: DAVIDSON, Julia; GOTTSCHALK, Petter (editors). Internet child abuse: current research and policy. Osfordshire: Routledge, 2011.

DURKIN, Keith F. Misuse of the Internet by pedophiles: implications for law enforcement and probation practice. Federal Probation, v. 61, Issue 3, Sept 1997.

ELIACHEFF, Caroline; LARIVIÈRE, Daniel Soulez. O Tempo das Vítimas. São Paulo: Fap/Unifesp, 2012.

ELIAS, Norbert. A Civilização dos Pais. Revista Sociedade e Estado, v. 27, n. 3, Setembro/Dezembro 2012.

ELIAS, Norbert. The civilizing process: sociogenetic and psychogenetic investigations. Massachusetts: Blackwell, 2000.

ELIAS, Norbert. Towards a theory of social processes: a translation. British Journal of Sociology, 48 (3), 1997, p. 355-383.

FINKELHOR, David. Child Sexual Abuse - new theory and research. New York: The Free Press; London: Collier Macmillan Publishers, 1984.

FULDA, Joseph S. Do Internet stings directed at pedophiles capture offenders or create offenders? And allied questions. Sexuality and Culture, v. 6(4), 2002, p.73-100.

GARLAND, David. On the concept of moral panic. Crime, Media, Culture, 4(1), 2008, pp. 9-30.

GRECO, Christopher A. P. "Falling back" on the Concept of (Moral) Panic: Questioning Significance, Practicality, and Costs. Doctoral thesis, Criminology, Faculty of Social Sciences, University of Ottawa, 2015.

GRECO, Christopher and CORRIVEAU, Patrice. La representation médiatique du leurre d'enfants à l'aide dês nouvelles technologies: une mise em mots et em maux. Ambigua, Revista de Investigaciones sobre Género y Estudios Culturales, n. 1, 2014, p. 35-56.

JENKINS, P. Failure to launch: Why do some social issues fail to detonate moral panics? British Journal of Criminology, 49, 2009, p. 35-47.

JENKINS, Philip. Beyond Tolerance - child pornography on the Internet. New York and London: New York University Press, 2001.

KRONE, Tony. A Typology of Online Child Pornography Offending. Trends \& Issues in crime and criminal justice. Australian Government; Australian Institute of Criminology, n. 279, 2004. 
LAMB, Michael. Cybersex: Research notes on the characteristics of the visitors to online chat rooms. Deviant Behavior, 19:2, 1998, p.121-135.

LANCASTER, Roger N. Sex panic and the punitive State. Berkeley, Los Angeles; London: University of California Press, 2011.

LANDINI, Tatiana Savoia e ZEYTOUNLIAN, Lauren. Assédio sexual on-line de crianças e adolescentes: abrindo o debate. In: DESLANDES, Suely Ferreira; CONSTANTINO, Patrícia. Exploração sexual de crianças e adolescentes: interpretações plurais e modos de enfrentamento. Rio de Janeiro: Hucitec, 2018, p. 129-172.

LANDINI, Tatiana Savoia. (2005), "Honra, horror e direitos - violência sexual contra crianças e adolescentes no século XX”. Tese de doutorado. São Paulo: FFLCH/USP.

LANDINI, Tatiana Savoia. Pedofilia e pornografia infantil: algumas notas. In:PISCITELLI, Adriana; GREGORI, Maria Filomena; CARRARA, Sérgio. Sexualidades e saberes: convenções e fronteiras. Rio de Janeiro: Garamond, 2004a, p. 319-342.

LANDINI, Tatiana Savoia. "A pornografia infantil na Internet - uma perspectiva sociológica”. In: Libório, Renata Coimbra Maria. A exploração sexual de crianças e adolescentes no Brasil. São Paulo: Casa do Psicólogo, 2004b, p. 165-182.

LOWENKRON, Laura. O monstro contemporâneo: a construção social da pedofilia em múltiplos planos. Rio de Janeiro, EdUERJ, 2015.

LOWENKRON, Laura. O monstro contemporâneo: notas sobre a construção da pedofilia como 'causa política' e 'caso de polícia' Cadernos Pagu, 41, julho-dezembro de 2013, p. 303-337.

MALESKY Jr, L. Alvin. Predatory online behavior: modus operandi of convicted sex offenders in identifying potential victims and contacting minors over the Internet. Journal of Child Sexual Abuse, v. 16 (2), 2007.

MARTELLOZZO, Elena. Understanding the perspetrators' online behavior. In: DAVIDSON, Julia; GOTTSCHALK, Petter (editors). Internet child abuse: current research and policy. Osfordshire: Routledge, 2011.

MCALINDEN, Anne-Marie. 'Grooming' and the Sexual Abuse of Children - institutional, Internet, and familial dimentions. Oxford, UK: Oxford University Press, 2012.

MISKOLCI, Richard. Pânicos morais e controle social. Cadernos Pagu, 28, 2007 101-128. MITCHELL, Kimberly J., WOLAK, Janis and FINKELHOR, David. Police posing as juveniles online to catch sex offenders: is it working? Sexual abuse: a journal of research and treatment, v. 17, n. 3, 2005, p. 241-267.

NATHAN, Debbie; SNEDEKER, Michael. Satan's silence: ritual abuse and the making of a modern american witch hunt. New York: Basic Books, 1995.

OST, Suzanne. Child pornography and sexual grooming: legal and societal responses. Cambridge, UK: Cambridge University Press, 2009.

PORTO, Maria Stella Grossi. Sociologia da Violência. Brasília: Verbana Editora, 2010. 
QUAYLE, Ethel; TAYLOR, Max. Child seduction and self-representation on the internet. CyberPsychology \& Behavior, v. 4, n. 5, 2001.

RODRIGUES, Robert. A pedofilia e suas narrativas: uma genealogia do processo de criminalização da pedofilia no Brasil. Rio de Janeiro: Editora Multifoco, 2017.

RUBIN, Gayle. Thinking Sex: Notes for a Radical Theory of the Politics of Sexuality. In: VANCE, Carole (ed.), Pleasure and Danger. Routledge \& Kegan: Paul, 1984.

SARTI, Cynthia Andersen. (2011), A vítima como figura contemporânea. Caderno CRH (UFBA. Impresso), v. 24, p. 51-61. SHANNON, David. Online sexual grooming in Sweden - online and offline sex offences against children as described in Swedish police data. Journal of Scandinavian Studies in Criminology and Crime Prevention, 9:2, 2008, 160-180.

SILVERMAN, Jon e WILSON, David. (2002), Innocence Betrayed: paedophilia, the Media and Society. Cambridge (UK), Polity Press.

SPIERENBURG, Peter. Violence and the civilizing process: does it work? Crime, Histoire \& Sociétés/Crime, History and Societies, v. 5 (2), 2001, p.87-105.

TARBOX, Katie. Katie.com: my story. New York: Plume (Penguin Group), 2001.

TAYLOR, Jon. Policing social networking sites and online grooming. In: DAVIDSON, Julia; GOTTSCHALK, Petter (editors). Internet child abuse: current research and policy. Osfordshire: Routledge, 2011.

VIGARELLO, Georges. História do Estupro. Rio de Janeiro: Jorge Zahar, 1998.

WOLAK, Janis, FINKELHOR, David; MITCHELL, Kimberly. Internet-initiated sex crimes against minors: implications for prevention based on findings from a National Study. Journal of Adolescent Health, 34, 2004, p. 424.e11- 424.e20.

YOUNG, Jock. Moral panics and the transgressive other. Crime, Media, Culture, 7(3), 2011, p. 245-258.

YOUNG, Jock. The Drugtakers: the Social Meaning of Drug Use, London: Judson, McGibbon and Kee, 1971.

\section{Documentos citados}

BILL C-277 An Act to amend the Criminal Code (luring a child). Disponível em: $<$ http://www.parl.gc.ca/Default.aspx?Language=E >. Acesso em: 03 jul. 2018.

BILL C-15A An Act to amend the Criminal Code and to amend other acts. Disponível em: $<$ http://www.parl.gc.ca/Default.aspx?Language=E $>$. Acesso em: 03 jul. 2018.

BILL C-22 An Act to Amend the Criminal Code (age of protection) and to make consequential amendments to the Criminal Records Act (2007). Disponível em: $<$ http://www.parl.gc.ca/Default.aspx?Language=E $>$. Acesso em: 03 jul. 2018. 
BRASIL. Código Penal - Decreto-lei n ${ }^{0}$ 2.848, de 7 de dezembro de 1940 (atualizado e acompanhado de legislação complementar). São Paulo: Saraiva, 2001.

ESTATUTO da Criança e do Adolescente. Disponível em: <http://www.planalto.gov.br/ ccivil_03/leis/L8069.htm>. Acesso em: 03 jul. 2018.

CRIMINAL Code of Canada. Disponível em: <http://laws-lois.justice.gc.ca/eng/ acts/C-46/>. Acesso em: 03 jul. 2018.

COUNCIL of Europe Convention on the Protection of Children against Sexual Exploitation and Sexual Abuse, 2007. Disponível em: <http://www.coe.int/en/web/ conventions/full-list/-/conventions/treaty/201>. Acesso em: 03 jul. 2018.

PEARSON, Landon. (Senator). Debates of the Senate, Edited Hansard 139(66). $37^{\text {th }}$ parliament $1^{\text {st }}$ Session, p. 1609, November $1^{\text {st }}, 2001$.

OWEN, Stephen. (Parliamentary Secretary to the Minister of Justice and Attorney General of Canada, Lib). Debates of the Senate, Edited Hansard 137(97). $37^{\text {th }}$ parliament $1^{\text {st }}$ Session, p. 6312, Octover, $18^{\text {th }}, 2001$.

TOEWS, Vic. (Provencher, Canadian Alliance). Debates of the Senate, Edited Hansard $137(97) \cdot 37^{\text {th }}$ parliament $1^{\text {st }}$ Session, p. 6314, Octover, $18^{\text {th }}, 2001$.

BLAIKIE, Bill. (Winnipeg_Transcona, NDP). Debates of the Senate, Edited Hansard $137(97) \cdot 37^{\text {th }}$ parliament $1^{\text {st }}$ Session, p. 6314, Octover, $18^{\text {th }}, 2001$.

STOFFER, P. (N.D.P.). House of Commons Debates, Edited Hansard 137(82). $37^{\text {th }}$ Parliament $1^{\text {st }}$ Session, p. 5353, September $20^{\text {th }}$, 2001. In: Greco, Christopher A. P. "Falling back" on the Concept of (Moral) Panic: Questioning Significance, Practicality, and Costs. Doctoral thesis. Department of Criminology, Faculty of Social Sciences, University of Ottawa, 2015.

\section{Relatórios Judiciais citados}

R. v. Bedford, [2008] O.J. No. 5760, Ontario Court of Justice, Kingston, Ontario, Oral judgment: March 14, 2008.

R. v. Bergeron, 2009 CarswellOnt 1352, 2009 ONCJ 104, 82 W.C.B. (2d) 259, Ontario Court of Justice, Heard: February 4, 2009, Judgment: February 4, 2009

R. v. Blanchard, [2003] O.J. No. 5510 No. 2632/03, Ontario Superior Court of Justice, Welland, Ontario, Oral judgment: December 17, 2003.

R. v. Bridgeman, 2011 ONCJ 117, Ontario Court of Justice, Heard: November 1, 2010 January 25, 2011, Judgment: February 18, 2011.

R. v. Brown, [2006] O.J. No. 1523, Ontario Superior Court of Justice, Heard: November 19, 2004; September 12-13, October 3, 2005; and January 25, 2006, Oral judgment: January 25, 2006. 
R. v. Brown, [2007] O.J. No. 3316, Ontario Court of Appeal, Toronto, Ontario, Heard: September 6, 2007, Judgment: September 7, 2007.

R. v. Dobson, [2013] O.J. No. 1358, Ontario Court of Justice, January 30, 2013.

R. v. Johnston, 2009 CarswellOnt 8378, 2009 ONCJ 628, [2009] O.J. No. 5697, 86 W.C.B. (2d) 186, Ontario Court of Justice, Heard: November 2,4, 2009, Judgment: December 23, 2009

R. v. Legare, [2009] 3 S.C.R. 551, [2009] 3 R.C.S. 551, Supreme Court of Canada, Heard: October 15, 2009; Judgment: December 3, 2009.

R. v. Saliba, [2013] O.J. No. 5887, Ontario Court of Appeal, Toronto, Ontario, Heard: October 16, 2013, Judgment: November 1, 2013.

R. v. Saliba, [2013] O.J. No. 6002, Ontario Court of Appeal, Toronto, Ontario, Heard: October 16, 2013, Judgment: November 1, 2013.

Recebido em 19/04/2017

Aprovado em 29/05/2018

\section{Como citar este artigo:}

LANDINI, Tatiana Savoia. Vulnerabilidade e perigo potencial - o processo de criminalização do assédio sexual online no Canadá e casos julgados em Ontário (20021014). Contemporânea - Revista de Sociologia da UFSCar, v. 8, n. 2, jul.- dez. 2018, pp. 515-542. 